\title{
Estudo do comportamento petrofísico das diferentes fácies do Granito Bannach, Suíte Jamon, Domínio Rio Maria
}

Groberio, L.S. ${ }^{1}$; Almeida, J.A.C. ${ }^{1}$; Tabosa, L.D.G. ${ }^{1}$; Lima, K.F.F. ${ }^{1}$; Leal, F.B. ${ }^{2}$; Branches, A.M.B. ${ }^{1}$

${ }^{1}$ Universidade Federal do Sul e Sudeste do Pará - UNIFESSPA, ${ }^{2}$ Universidade Federal de Campina Grande - UFCG

Copyright 2018, SBGf - Sociedade Brasileira de Geofísica

Este texto foi preparado para a apresentação no VIII Simpósio Brasileiro de Geofísica, Salinópolis, 18 a 20 de setembro de 2018. Seu conteúdo foi revisado pelo Comitê Técnico do VIII SimBGf, mas não necessariamente representa a opinião da SBGf ou de seus associados. É proibida a reprodução total ou parcial deste material para propósitos comerciais sem prévia autorização da SBGf.

\section{Resumo}

O Granito Paleoproterozóico Bannach pertence à Suite Jamon, Domínio Rio Maria, porção sul da Província Carajás. Estudos geológicos apontam que a textura grossa (fácies $A B M z G$ e $L M z G$ ) forma o relevo arrasado e plano, enquanto a textura fina (fácies LMzM e LMzF) forma as serras e morros. Através de testes laboratoriais determinou-se as características físicas de ambas as fácies, como a porosidade $(<1,85 \%)$, a densidade $(2,52$ a $\left.2,62 \mathrm{~g} / \mathrm{cm}^{3}\right)$, as velocidades compressional e cisalhante (geralmente entre 5400 e $6000 \mathrm{~m} / \mathrm{s}$ para as ondas $\mathrm{P}$ e entre 3000 e $4000 \mathrm{~m} / \mathrm{s}$ para as ondas S) e o índice de resistência das fácies grossas (2,96 a 4,70 Mpa) e das fácies finas (5,31 até 9,85 MPa). Esses resultados contribuem significativamente para explicar 0 comportamento geomorfológico das fácies texturais do Granito Bannach, uma vez que as fácies de granulação grossa, por apresentar baixa resistência e maior suscetibilidade ao intemperismo físico e erosão, tendem a ocupar áreas topograficamente arrasadas e planas, ao passo que as fácies de granulação mais fina são mais resistentes e menos suscetível à erosão, arquitetando as serras e morros do Granito Bannach.

\section{Introdução}

Durante o Paleoproterozoico, a Província Carajás (VASQUEZ et al., 2008) foi palco de um intenso magmatismo anorogênico com várias intrusões de granitos do tipo-A oxidados (DALL'AGNOL et al., 2005). No Domínio Rio Maria, porção sul da Província Carajás, este evento é marcado pela Suíte Jamon (DALL'AGNOL et al., 2005) representada pelos Granitos Jamon (DALL'AGNOL et al., 1999), Musa (GASTAL, 1987), Marajoara (ROCHA JR, 2004), Manda Saia (LEITE, 2001), Redenção (OLIVEIRA, 2001) e Bannach (ALMEIDA et al., 2006). Estes granitos quando datados pelos métodos $\mathrm{U} / \mathrm{Pb}$ e $\mathrm{Pb} / \mathrm{Pb}$ em zircões e $\mathrm{Pb} / \mathrm{Pb}$ em rocha total, fornecem idades de cristalização e colocação próximas de 1,88 Ga (MACHADO et al., 1991; BARBOSA et al., 1995; DALL'AGNOL et al., 1999; DALL'AGNOL et al., 2002).

Diversos estudos sobre estes granitos apontam que a textura das diferentes fácies é a responsável pela geomorfologia destes plutons, onde as fácies de granulação grossa ocupam domínios arrasados do relevo, enquanto aquelas mais finas constituem as regiões de morros e serras desses corpos. A composição mineralógica das fácies é outro fator que controla a geomorfologia, sendo que as fácies com maior conteúdo de máficos estão presentes em áreas topograficamente planas e as mais leucocráticas em regiões acidentadas. Essas observações são baseadas em dados geológicos e de campo, não havendo nenhum estudo direcionado para determinar as características físicas envolvendo porosidade, densidade, velocidades sísmicas e, nem tampouco, testes geomecânicos para avaliar a resistências dessas rochas. Um estudo desta natureza pode contribuir para entender a relação existente entre os processos erosivos e as características físicas das diferentes fácies e com isso explicar o controle da paisagem na área de ocorrência destes plutons. Outra contribuição deste estudo é a quantificação do grau de anisotropia, uma vez que as texturas desses granitos não apresentam orientação preferencial dos seus grãos, sendo classificadas estruturalmente como granitos isotrópicos, sem, no entanto, haver quantificação do grau de anisotropia. Deste modo, a presente pesquisa direciona-se para determinar os parâmetros físicos do Granito Bannach, a fim de buscar explicações para a resposta do comportamento geomorfológico do pluton. Este batólito está localizado na porção oeste do Domínio Rio Maria, e é formado essencialmente por rochas monzograníticas isotrópicas, tendo sido distinguidos três grandes conjuntos petrográficos (ALMEIDA et al., 2006): a) fácies de granulação grossa portadoras de anfibólio + biotita \pm clinopiroxênio; b) fácies portadora de biotita com textura porfirítica e c) fácies leucograníticas, com termos grossos, médios e finos.

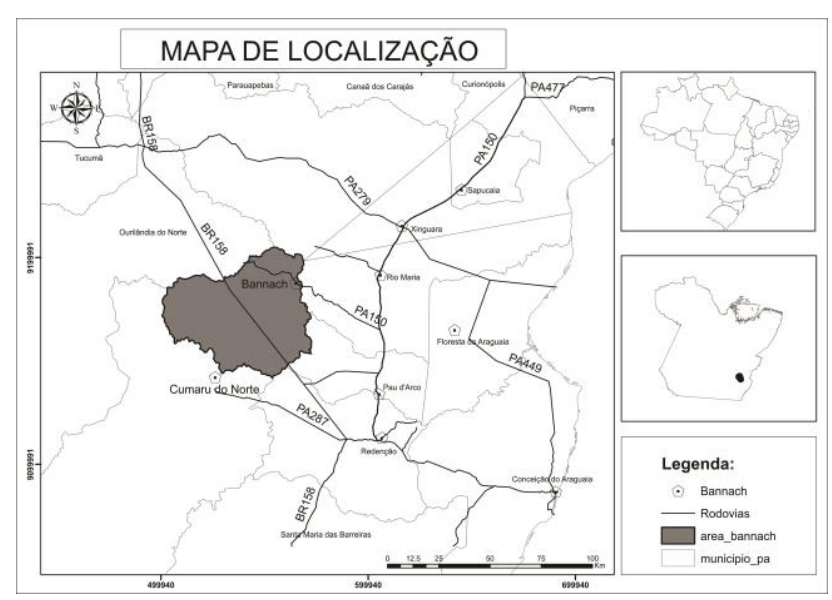

Figura 1 - Mapa de localização. 


\section{Metodologia}

Todas as amostras utilizadas neste trabalho foram plugues cilíndricos, preparados a partir de amostras de mão coletadas em afloramentos. A preparação dos plugues e a determinação da densidade, da porosidade e das velocidades elásticas das amostras foram realizadas no LabPetro-UFCG (Laboratório de Petrofísica da Universidade Federal de Campina Grande). Para a preparação dos plugues foram utilizados uma serra, para adequar os blocos de rocha, uma plugadeira de bancada e uma retificadora, para garantir faces planas e paralelas. Após esta fase os plugues são submetidos à secagem por 24 horas sob temperatura constante de $80^{\circ} \mathrm{C}$ em estufa. Em seguida, são pesados em balança eletrônica de precisão e realizadas as medidas de suas dimensões, para o cálculo do volume total e densidade.

A densidade de grão e a porosidade foram obtidas utilizando um porosímetro a gás conectado em um matrix cup, através da porosimetria por expansão gasosa. Neste método o que é medido é o volume de grãos, que permite o cálculo da densidade de grãos. Já o volume poroso é calculado como a diferença entre o volume total e o volume de grãos, permitindo o cálculo da porosidade.

Velocidades compressionais e cisalhantes foram medidas utilizando uma câmara de alta pressão (sistema Autolab500® - New England Research), à temperatura ambiente e com o sistema da pressão de poros aberto para a atmosfera. As velocidades foram registradas para pressões confinantes variando de 500 a 3000 psi. Neste sistema são registradas três ondas que se propagam ao longo da direção axial do plugue: uma onda compressional e duas ondas cisalhantes mutuamente ortogonais.

Para os ensaios geomecânicos foi utilizado o teste de carga pontual com o equipamento da Martins \& Campelo, modelo PLT/M-100. O teste de carga pontual foi conduzido de acordo com a Sociedade Internacional de Mecânica das Rochas (ISRM) - Método de Teste Padrão para Determinação do Îndice de Força de Carga Pontual. Os dados foram, então, processados e comparados através de gráficos e tabelas.

\section{Resultados}

Os dados de densidade dos grãos ( $\rho G)$, densidade total $(\rho B)$, porosidade $(\Phi)$, velocidade de compressão (VP) e velocidade cisalhantes (VS1 e VS2) são apresentados na Tabela 01. Os valores de $\rho B$ variam entre 2,52 a $2,62 \mathrm{~g} / \mathrm{cm}^{3}$, sendo compatíveis, de acordo com a literatura, para granitos. Os maiores valores de $\rho B$ relacionam-se as fácies $A B M z G$, as quais são portadoras de anfibólio e biotita. Os valores da densidade dos grãos são maiores que a da densidade total, pois excluem os valores dos espaços vazios e dos fluídos presentes na rocha. Como esperado para granitos, a porosidade é baixa, sendo menor do que 1,85\%, com exceção da amostra AD-48, que apresenta valor de 3,09\%. Não há uma relação clara entre 0 aspecto textural com a porosidade das rochas, ou seja, os valores das fácies de granulação grossa intercalam-se com aqueles das rochas de granulação fina e média. Utilizando uma pressão de 3000 psi, a velocidade compressional (VP) apresentou em sua maioria, valores dentro do padrão de rochas graníticas (5500-6000 m/s), apenas as amostras ADR-25 e ADR-13 exibiram valores ligeiramente inferiores ao esperado para esse tipo de rocha. Os resultados da velocidade cisalhante, VS1 e VS2, não apresentam variações expressivas entre seus valores, mostrando que as ondas se propagaram em meios, provavelmente, isotrópicos.

Tabela 01 - Parâmetros físicos medidos e calculados.

RESULTADOS DOS PARÂMETROS FÍSICOS

\begin{tabular}{cccccccc}
\hline Fácies & Amostra & $\boldsymbol{\rho G}\left(\mathbf{g} / \mathbf{c m}^{3}\right)$ & $\mathbf{\rho} \mathbf{( g / \mathbf { c m } ^ { 3 } )}$ & $\boldsymbol{\Phi ( \% )}$ & $\mathbf{V P}(\mathbf{m} / \mathbf{s})$ & VS1 $(\mathbf{m} / \mathbf{s})$ & $\mathbf{V S 2}(\mathbf{m} / \mathbf{s})$ \\
\hline (AB)MzG & AD-98 B & 2.655 & 2.62 & 1.15 & 5583 & 3568 & 3420 \\
\hline \multirow{4}{*}{ LMzG } & ADR-31 B & 2.635 & 2.59 & 1.70 & 5465 & 3652 & 3411 \\
& ADR-32 B & 2.615 & 2.59 & 0.84 & 5552 & 3397 & 3397 \\
& AD-120 & 2.62 & 2.58 & 1.47 & 5589 & 3290 & 3328 \\
\hline \multirow{6}{*}{ LMzM } & AD-140 & 2.603 & 2.56 & 1.75 & 5771 & 3419 & 3463 \\
& AD-48 & 2.603 & 2.52 & 3.09 & 5406 & 3277 & 3382 \\
& AD-202 & 2.617 & 2.60 & 0.83 & 5710 & 3482 & 3448 \\
& ADR-35 B & 2.601 & 2.59 & 0.42 & 5955 & 3725 & 3877 \\
& ADR-13 & 2.597 & 2.54 & 1.02 & 5161 & 3086 & 3181 \\
\hline LMzF & ADR-25 & 2.599 & 2.55 & 1.85 & 5086 & 3119 & 3119 \\
\hline
\end{tabular}

Com os resultados obtidos pelo teste de carga pontual, os índices de resistência (Is (50)) das amostras foram calculados e são exibidos na Tabela 02. As medidas variam entre 2,96 a 9,85 $\mathrm{MPa}$, este último valor considerado anômalo, pois a maioria das amostras exibem valores menores do que $6,5 \mathrm{MPa}$. A relação existente entre os índices de resistência e os aspectos texturais das rochas é evidente, onde nota-se que as fácies de granulação grossa apresentam valores desses índices comparativamente mais baixo $(<4,7 \mathrm{MPa})$ do que as fácies de granulação mais fina (>5,3 MPa).

Tabela 02 - Parâmetros geomecânicos

PARÂMETROS GEOMECÂNICOS

\begin{tabular}{ccc}
\hline Fácies & Amostra & IS(50) (MPa) \\
\hline$(\mathrm{AB}) \mathrm{MzG}$ & AD-98 B & 4.701 \\
\hline \multirow{3}{*}{ LMzG } & ADR-31 B & 2.965 \\
& ADR-32 B & 4.179 \\
& AD-120 & 4.652 \\
\hline & AD-140 & 6.313 \\
& AD-48 & 6.460 \\
LMzM & AD-202 & 5.306 \\
& ADR-35 B & 9.857 \\
& ADR-13 & 4.276 \\
\hline LMzF & ADR-25 & 7.106 \\
\hline
\end{tabular}

Na figura 02 estão plotadas as amostras com os valores da razão das velocidades cisalhantes S1 e S2. Essa razão é utilizada para calcular o grau de anisotropia da rocha. Como as ondas cisalhantes S1 e S2 são polarizadas perpendicularmente e se propagam na 
mesma direção, ao atravessar um meio isotrópico as mesmas não devem sofrer atrasos em seus percursos, refletindo em razões $\mathrm{S1/S2}$ próxima a unidade. No entanto, quando essas ondas percorrem rochas anisotrópicas, onde cristais apresentam orientações preferenciais em uma determinada direção, as ondas cisalhantes S1 e S2 propagam-se com velocidades bastante distintas, resultando em razões S1/S2 distantes da unidade. Os valores apresentados estão em sua maioria próximos de 1 , variando de mais ou menos $5 \%$.

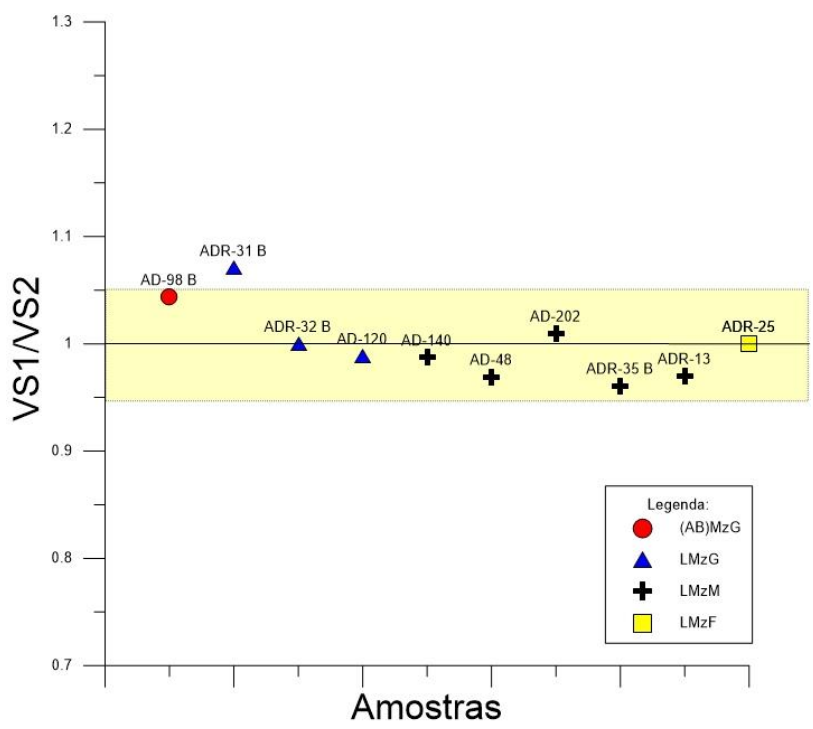

Figura 02 - Gráfico da razão entre as velocidades cisalhantes para as amostras das diferentes fácies.

$\mathrm{Na}$ figura 03, é apresentada a relação entre os valores do índice de resistência das amostras com a textura das rochas estudadas. Nota-se que as fáceis de granulação grossa apresentam baixa resistência $(<4,7 \mathrm{MPa})$, ao passo que as fácies de granulações médias e fina mostram resistência comparativamente mais elevada ( $>5,3 \mathrm{MPa})$. De acordo com os resultados dos testes de carga pontual percebe-se que as fácies de granulação mais fina necessitam de maiores tensões para se deformarem, já para as de granulação grosseira, tensões menos intensas são suficientes para deformá-las e fraturá-las.

\section{Discussão e Conclusões}

Os testes de PLT no conjunto estudado mostram que o índice de resistência das amostras com textura grossa (ABMzG e LMzG) do Granito Bannach apresentam baixa resistência, com valores concentrados entre 2,96 a 4,70 $\mathrm{MPa}$, ao passo que as rochas com granulação mais fina (LMzM e LMzF) são mais resistentes apresentando valores de 5,31 até $9,85 \mathrm{MPa}$. Esses resultados contribuem significativamente para explicar 0 comportamento geomorfológico das fácies texturais do Granito Bannach, uma vez que as fácies de granulação grossa, por apresentar baixa resistência e maior suscetibilidade ao intemperismo físico e erosão, tendem a ocupar áreas topograficamente arrasadas e planas, ao passo que as fácies de granulação mais fina (LMzM e LMzF) são mais resistentes e menos suscetível à erosão, arquitetando as serras e morros do Granito Bannach.

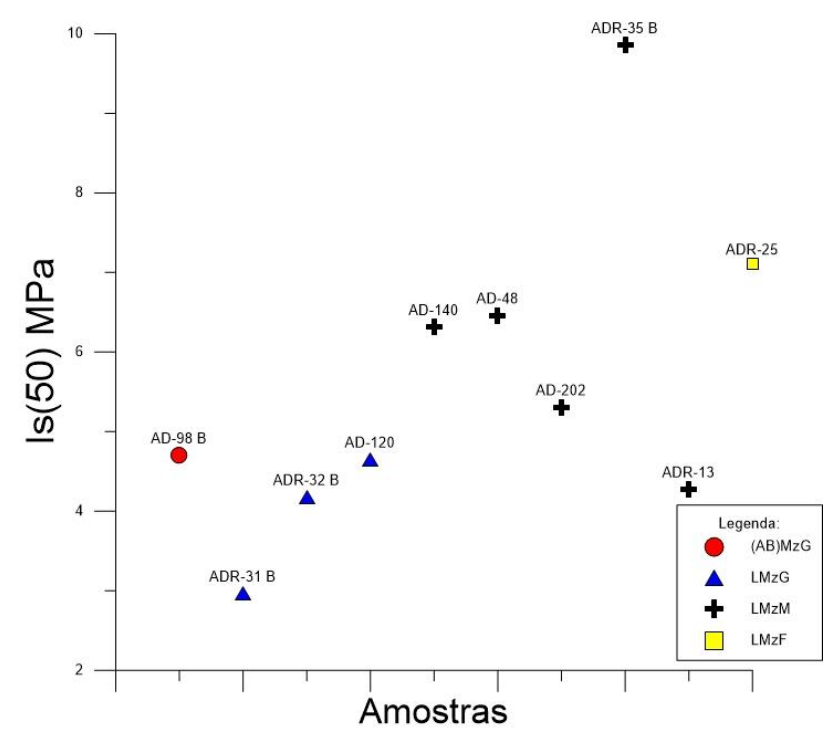

Figura 03 - Gráfico do Índice de Resistência para as amostras das diferentes fácies.

Os índices de resistência estão relacionados com a porosidade das rochas, porém não há uma clara distinção dos valores de porosidade das diferentes fácies do Granito Bannach. Assim, a relação existente entre a textura e resistência dessas rochas é dada pela a granulação das mesmas. As dimensões dos cristais influenciam diretamente nas propriedades mecânicas das rochas, em especial a dureza, a resistência à corrosão e - limite de escoamento. Os cristais de uma rocha possuem diferentes orientações cristalográficas e, durante a deformação plástica, o escorregamento ou o deslocamento de discordâncias deve ocorrer ao longo dos contornos dos cristais, os quais funcionam como uma barreira a estes deslocamentos, por duas razões: 1) Como os dois grãos possuem diferentes orientações cristalográficas, a discordância, ao passar de um grão $A$ para um grão $B$, precisa alterar sua direção de deslocamento, o que se torna mais difícil a medida que as desorientações aumentam; b) A desordem atômica nos contornos de grão resulta na descontinuidade dos planos de escorregamento entre um grão e outro. Deste modo, uma rocha com grãos mais finos possui maior dureza e resistência mecânica do que rochas de granulação grosseira, pois os primeiros possuem maior número de contornos de grão. 


\section{Agradecimentos}

Os autores agradecem ao projeto Levantamento de Propriedades Físicas e Mecânicas das Rochas $n^{\circ} 027 / 2016$ IGE / UNIFESSPA, do qual este trabalho é parte integrante; ao Laboratório de Petrofísica da Universidade Federal de Campina Grande pela realização dos ensaios petrofísicos e a Vale S/A pela realização dos ensaios geomecânicos.

\section{Referências}

Almeida, J.A. C. 2005. Geologia, Petrografia e Geoquímica do Granito Anorogênico Bannach, Terreno Granito-Greenstone de Rio Maria-Pará. Centro de Geociências, Universidade Federal do Pará, 170p. (Dissertação de Mestrado)

Almeida, J.A.C.; Dall'agnol, R.; Oliveira, D.C. 2006. Geologia, Petrografia e Geoquímica do Granito Anorogênico Bannach, Terreno Granito-Greenstone de Rio Maria, Pará. Revista Brasileira de Geociências, 36:282-295

Broch E. and Franklin J.A. 1972. The Point Load Strength Test. International Journal of Rock Mechanics and Mineral Sciences. 9(6): 669-676

Barbosa, A.A.; Lafon, J.M.; Neves.A.P.; Vale, A.G. 1995. Geocronologia Rb-Sr e Pb-Pb do Granito Redenção, SE do Pará: implicações para o magamatismo proterozóico da região de Redenção. Boletim do Museu Paraense Emílio Goeldi, 7: 147-164.

Bowden, P. \& Kinnaird, J.A. 1984. Geology and mineralization of the Nigerian anorogenic ring complexes. Geol. Jahrb., B56:3-65

Dall'agnol R., Ramö O.T. Magalhães M.S., Macambira M.J.B. 1999. Petrology of the Anorogenic, Oxidised Jamon and Musa Granites, Amazonian Craton: Implications for the genesis of Proterozoic, AType Granites. Lithos., 46: 431-462.

Dall'agnol, R., Oliveira, D.C., Macambira, M.J.B., Lamarão, C.N. 2002. Diques proterozóicos do Terreno Granito-Greenstone de Rio Maria: A descoberta de diques compostos e novos dados geocronológicos. In: SIMP. VULC. AMB. ASSOC, 2., Belém. Boletim de resumos e roteiros da excursão. Belém, UFPA. Núcleo PRONEX do Centro de Geociências, p.13.

Dall'agnol R., Teixeira N.P., Rämö O.T., Moura C.A.V., Macambira M.J.B., OLIVEIRA D.C.O. 2005. Petrogenesis of the Paleoproterozoic Rapakivi A-type granite of the Archean Carajás Metallogenetic Province, Brazil. Lithos. 80: 101-129.

DOCEGEO. 1988. Revisão litoestratigráfica da Província Mineral de Carajás. In: SBG, Cong. Bras. Geol., 35. Belém, p.11-54.
Farmer, I. W. (1968). Engineering Properties of Rocks. Spon Editors, London.

Gastal, M.C.P. 1987. Petrologia do Maciço Granítico Musa, sudeste do Pará. Dissertação de Mestrado, Centro de Geociências, Universidade Federal do Pará. 316 p.

Hoek, E. 2000. Practical Rock Engineering. Edition, http://www.rocscience.com

ISRM, International Society of Rock Mechanics Commission on Testing Methods, 1985. Suggested Method for Determining Point Load Strength. International Society for Rock Mechanics.

Kearey, P.; Brooks, M.; Hill, I. Geofísica de Exploração. São Paulo - Oficina de textos,2009.

Leite A.A.S. 2001. Geoquímica, petrogênese e evolução estrutural dos Granitóides Arqueanos da Região de Xinguara, SE do Cráton Amazônico. Dissertação de Doutorado, Centro de Geociências, Universidade Federal do Pará, 330p.

Machado, N.; Lindenmayer, Z.G.; Krogh, T.E.; Lindenmayer; $\mathrm{D}$. U-Pb geochronology of Archean magmatism and basement reactivation in the Carajás area, Amazon shield, Brazil. Precambrian Res., 49, 329354. 1991.

Martins, F. F., Pinheiro, Miranda, T. F. S. (2012), Correlações entre algumas propriedades mecânicas de rochas graníticas com vista à escavação de túneis, Revista della Associazione Georisorse e Ambiente, 104: 247-249.

Tabosa, L. D. G. Atenuação elástica das rochas da Bacia do Rio do Peixe. 124 p. Campina Grande, Universidade Federal de Campina Grande. Centro de Tecnologia e Recursos Naturais. Programa de Pós-Graduação em Exploração Petrolífera e Mineral. (Dissertação de Mestrado)

Tiab, D.; Donaldson, E.C. 2004. Petrophysics. Theory and practice of measuring reservoir rock and fluid transport properties. Elsevier.

Vasquez, M. L., Rosa-Costa, L. T., Silva, C. G., Ricci, P. F., Barbosa, J. O., Klein, E. L., Lopes, E. S., Macambira, E. B., Chaves, C. L., Carvalho, J. M., Ooliveira, J. G., Anjos, G. C., Silva H. R. 2008. Geologia e recursos minerais do estado do Pará: Sistema de Informações Geográficas - SIG: Texto explicativo dos mapas Geológico e Tectônico e de Recursos Minerais do Estado do Pará. In: M. L. VASQUEZ, \& L. T. ROSA-COSTA, (Orgs.): Escala 1:1.000.000: 1-329. CPRM, Belém. 


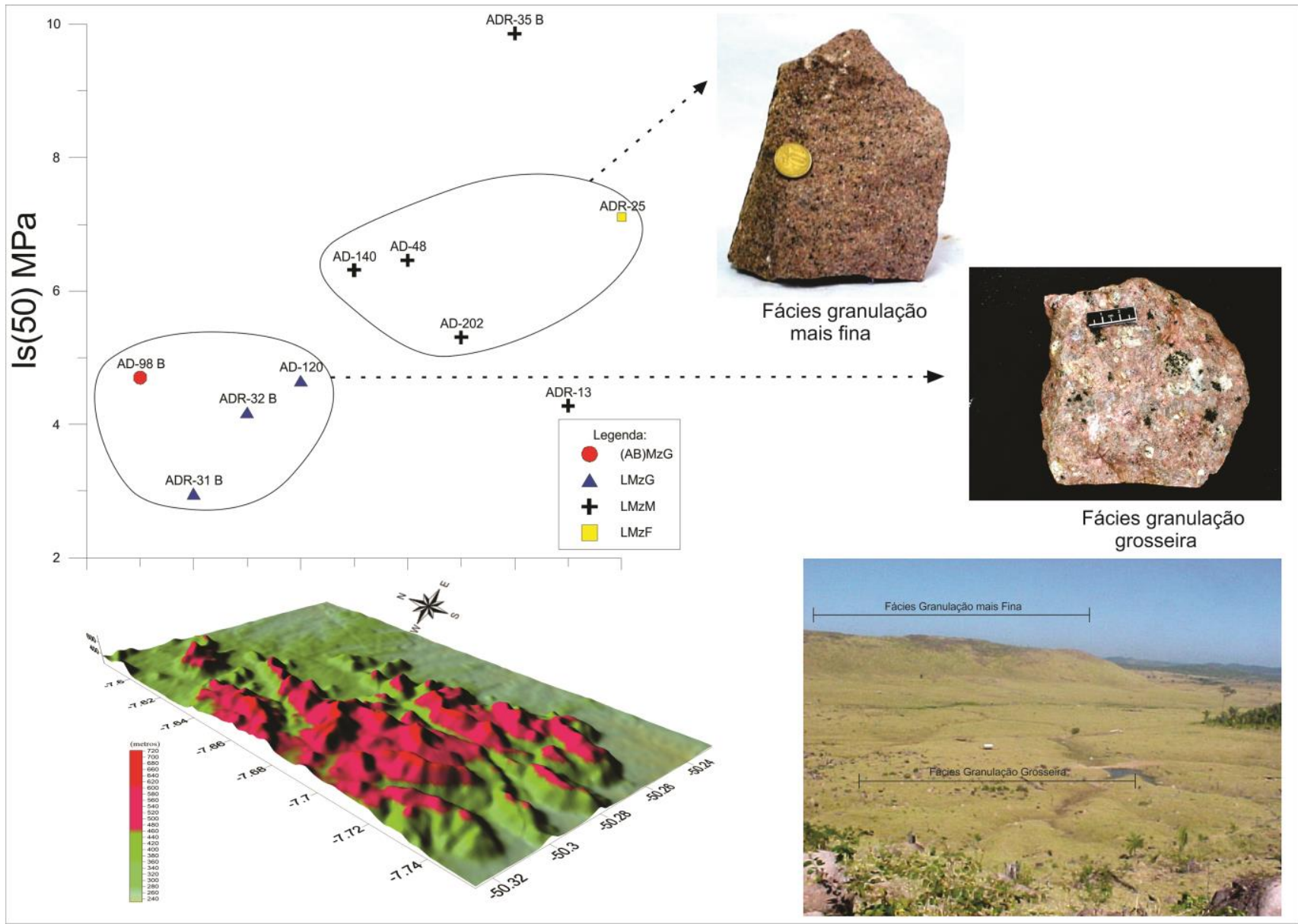

Figura 04 - Índice de resistência, amostras e relevo do Granito Bannach. 